\title{
Space Structure of Smart Land Use in Maanshan Based on Buffer Extention
}

\author{
Shenmin Wang*, Qifang Ma, Wenqi Liu and Xinyue Zhang \\ School of Geography and Remote Sensing, Nanjing University of Information Science \& Technology, Nanjing 210044, China \\ ${ }^{*}$ Corresponding author
}

\begin{abstract}
The research of land suitability evaluation based on GIS using buffer diffusion methods, to optimize the Ma ' Anshan city's intensive land-use spatial structure in order to achieve The highest land use efficiency, meet requirements of the smart use of land. Research results indicate that Ma ' Anshan Industrial land should be radiate from the urban to the surrounding, some Industrial land in the urban area may converted into corresponding commercial land and residential land, industrial in mining area should accumulated development to formed industrial zone , conurbation in southern area of the city should appropriately increased commercial land.
\end{abstract}

Keywords- land use; suitability evaluation;GIS; maanshan

\section{INTRODUCTION}

Smart growth is a concept of urban planning, which gradually became popular in the United States in the late 1990s, and was later cited and studied by scholars from various countries around the world [1-2]. Some scholars in China have translated it as "rational growth" and "smart growth", which reflects the concept and strategy of a compact urban space expansion [3-4].

Of Wisconsin 30 and smart growth policies related to the integrated planning for statistical analysis, from the community scale to include the protection of open space, farmland and environment sensitive areas; urban renewal and redevelopment, including six smart growth strategies were comparative evaluation by Edwards and Haines[5]. Ren Kui and Shen Wei[6-9] smart growth theory to optimize the allocation of land based structure, Cao Wei constructs the index system of urban and rural land use and smart, smart urban and rural land use patterns are discussed[10-11].Wang Junling put the smart growth theory into urban stock land filled with study, in Zhumadian City of Henan Province as an example, using RS and GIS technology, based on the stock of land survey and analysis, the stock of land filling capacity was estimated, and the stock of land filled before and after the land set about using level, urban scale and urban growth boundary growth were compared and analyzed[12].

Integrated view, the land smart use, mostly around the amount of land smart use, intensive use of land and so on, in the space optimization of significantly less, but the space optimization research is particularly important for urban development, this paper intends to in Maanshan City as an example, on the land smart use theory based, through a combination of Maanshan city space structure analysis proposed in Maanshan City Smart land use spatial structure optimization scheme.

\section{RESEARCH METHODS AND IDEAS}

\section{A. Research Methods}

\section{1) Suitability evaluation method}

Land suitability evaluation is a specific type of spatial location area problem. The main idea of GIS land suitability evaluation is for specific units of land, the reasonable division for a certain number of evaluation unit, the integration of multiple quantitative data of different impact factor for the evaluation unit of land use suitability of the influence degree. Finally, through the overlay will be different aspects of the economic, social and ecological factors was performed to quantify the effects of comprehensive, finally get the evaluation unit for a suitable quantitative evaluation of specific land use direction.

\section{2) The analytic hierarchy process}

AHP method is a qualitative and quantitative analysis method of combining the multi-objective decision analysis method. The main idea of this method is through the complex problem decomposition for a number of levels and a number of factors and how important it is for pairwise index between make comparative judgment, the judgment matrix is established. By calculating the biggest characteristic of judgment matrix values and corresponding eigenvectors, can get the weights of different indexes in evaluating the degree of importance, and for land suitable evaluation provides a quantitative standard ${ }^{[16-18]}$.

\section{3) Buffer diffusion method}

Buffer diffusion method is to point to in GIS system operation, for a influential facilities, the facilities as the center, given several different radius of the circle, by the circular forms a ring, each ring is buffer, in the same circle area have the same buffer value, is a kind of influence degree of assignment method. According to the distance will divide the land into different grades, so that it can obtain various attributes of a single layer of data and based on raster data structure, the single layer buffer were overlapped and calculated. Finally, it obtains the land suitability and spatial optimization of comprehensive layer. 


\section{B. Research Ideas}

Smart spatial structure of land use in the study of land use suitability evaluation based on the current situation, by adjusting the current land use types to achieve ecological urban construction and maximum urban benefit. Firstly, the use of buffer diffusion method in the study area land suitability evaluation, and then on the basis of the evaluation results, the control status of land use, land use study of the spatial coordination, land type conversion costs in respect of the establishment of appropriate value layer Finally, the Overlay get comprehensive land use sophisticated spatial structure optimization results Draw Overall research framework paper on the basis of the above analysis, shown in Figure 2.1.

\section{RESEARCH PROCESS}

\section{A. Suitability Evaluation Model}

The land suitability evaluation model based on GIS, first of all, according to the research needs and precision of data accuracy study area can be divided into reasonable evaluation unit; Secondly, the construction of a scientific land suitability evaluation index system; Again, is clear about the influence of different factors of quantitative method and comprehensive method; Finally, by ArcGIS software platform is calculated and the evaluation results such as spatial visualization.

\section{B. Division of Evaluation Unit}

Evaluation unit is the basic spatial unit land evaluation objects, basic properties and quality of basic unit interior land, large difference between the unit and the unit. Land suitability evaluation is based on the result of the evaluation unit of each attribute of land evaluation, therefore, the division of evaluation unit for the implementation of the land suitability evaluation is particularly important.

At present, based on geographic information system of urban land evaluation unit selection of basically has two kinds: vector polygon method is selected in different factor layer space vector data overlay analysis basis, according to the combination of evaluation factors corresponding to determine the size of the polygon; Grid selection principle. these led the raster data in the study area will be the study area is divided into a certain number of certain rules of same size grid, to evaluate the grid as a unit. The advantages of this method is to reduce subjectivity, conducive to graphic space superposition algorithm and model calculations; Each grid can extract information sources, but also shows that the evaluation results.

\section{The Selection of Evaluation Indexes and the Weight}

\section{1) Selection of index factor}

When making suitability index factor selection should follow the following principles:

- Affect sexual principle, namely the selection of index factor has a big influence on land productivity;

- Spatial variation principle, namely the selection in the evaluation of the characteristics of index factor of area has great spatial variability within the scope;
- Stability and accessibility principle, that is, the selection of the characteristics of index factor of time is relatively stable, index data available.

\section{2) Index system of building}

Residential land suitability evaluation index system in general can be divided into land use types, social and economic factors, ecological environment these three types of indicators, including the selection and industrial land distance as the evaluation of the ecological environment factor.

Based on industrial land to the requirement of resource and transportation condition, selection of natural conditions, industrial agglomeration, infrastructure, land use type four categories of indicators.

Demographic factors and business for commercial land, the cluster so selected including population density, traffic and large shopping plaza, and Banks have larger influence on distribution of commercial land evaluation factors.

The characteristics of agricultural land is different from other land lies in its distribution is mainly affected by natural conditions and water conservancy and other infrastructure, so choose natural factors as evaluation factors and infrastructure. The concrete index system build results see table4.1.

\section{3) The index factor determining weight}

Adopt the analytic hierarchy process (ahp) to determine the weight of each factor, each system and using software yaahp weight value is calculated. The main operating process as: In the first place in the hierarchy model of constructing index system hierarchy model under the window, the four categories of disciplines respectively as the decision objective, evaluation factors as an intermediary factor, appraisal factor as alternative option value; Then the construction of judgment matrix, respectively between evaluation factors and the evaluation factors of evaluation factor between the relative important degree, the importance of here based on the research achievements of predecessors for land suitability evaluation and comprehensive income opinions from relevant research experts; The last factor weight shown in the results window directly, factor weight in "show details" TAB.

\section{The Layer Formation and Superposition}

1) Land suitability evaluation in this article is to choose the different land use types as the target of evaluation, according to the land quality differences and different ways of land use of ecological, social requirements, to meet the established under the condition of hard constraints, analysis the process of land suitability. In the evaluation process, in order to more convenient and follow-up work in the suitability assessment, raster grid unit of analysis as the basic unit of evaluation, spatial diffusion method of buffer is adopted to establish the corresponding to the different index system of a single layer.

2) For single layer grid with different levels of suitability for assignment operation, and then will be involved in the various land use types related grid overlay layer, grid values of superposition after heavy after classification and grading, get 
the suitability of various types of land distribution layer and repeated raster superimposed on the suitability of distribution layer operation, eventually get comprehensive savvy land use suitability evaluation results in the study area.

\section{E. Suitability Evaluation Result Analysis}

For smart land use suitability evaluation results, based on raster data statistics, statistics of various land use types in the study area, the number of grid units and then through the grid of classification and assign scores operation, superposition of suitability score layer, and then analyzes and summarizes the research in different types of land use suitability spatial distribution, determine the most appropriate smart land use spatial structure.

\section{F. Balanced Score Analysis}

According to in the process of land use spatial optimization, various types of land use in ensuring maximum satisfy the suitability of the at the same time, reasonable distribution of different land use types within cities, is also very important to coordinate with each other. Influence is different between different units, engaged in related research in literature and consult experts, on the basis of the index of coordination between different land use types determine the space optimization coordinate matrix as follows:

TABLE I. COORDINATE MATRIX SPACE OPTIMIZATION

\begin{tabular}{ccccc}
\hline & $\begin{array}{c}\text { Industria } \\
\text { l land }\end{array}$ & $\begin{array}{c}\text { Residential } \\
\text { land }\end{array}$ & $\begin{array}{c}\text { Agricultural } \\
\text { land }\end{array}$ & $\begin{array}{c}\text { Commerci } \\
\text { al land }\end{array}$ \\
$\begin{array}{c}\text { Industrial } \\
\text { land }\end{array}$ & 10 & 4 & 3 & 6 \\
$\begin{array}{c}\text { Residential } \\
\text { land }\end{array}$ & 4 & 10 & 8 & 8 \\
$\begin{array}{c}\text { Agricultural } \\
\text { land }\end{array}$ & 3 & 8 & 10 & 6 \\
$\begin{array}{c}\text { Commercial } \\
\text { land }\end{array}$ & 6 & 8 & 6 & 10
\end{tabular}

First of industrial land, residential land, agricultural land and commercial land use, land space was used to optimize the value in the coordinate matrix to heavy classification, the status quo of the layer to get corresponding results; Then using GIS in the neighborhood of statistical tools for each grid numerical sum of eight adjacent grid, the grid values according to level 3 heavy classification, value from big to small, respectively, assigned to 3, 2, 1 minute, respectively extracted from the status quo of the picture four types of land use, and the four land rasterize processing and numerical summation, get the corresponding results; To finally get together after four corresponding processing picture made into a new layer is the coordination layer.

\section{G. Conversion Cost Score Analysis}

In the process of land space optimization, some units of land use type change, resulting in a type conversion costs.With reference to predecessors' for the land type conversion costs of research and opinions from relevant experts, determine the land type conversion cost matrix as follows:
TABLE II. CONVERSION COST MATRIX

\begin{tabular}{|c|c|c|c|c|}
\hline & $\begin{array}{c}\text { Industrial } \\
\text { land }\end{array}$ & $\begin{array}{l}\text { Residential } \\
\text { land }\end{array}$ & $\begin{array}{l}\text { Agricultural } \\
\text { land }\end{array}$ & $\begin{array}{c}\text { Commercial } \\
\text { land }\end{array}$ \\
\hline $\begin{array}{c}\text { Industrial } \\
\text { land }\end{array}$ & 0 & 0.6 & 0.8 & 0.4 \\
\hline $\begin{array}{l}\text { Residential } \\
\text { land }\end{array}$ & 0.8 & 0 & 0.5 & 0.6 \\
\hline $\begin{array}{l}\text { Agricultural } \\
\text { land }\end{array}$ & 0.6 & 0.5 & 0 & 0.4 \\
\hline $\begin{array}{c}\text { Commercial } \\
\text { land }\end{array}$ & 0.6 & 0.4 & 0.4 & 0 \\
\hline
\end{tabular}

Based on the present status and suitability of various land use map, use cost transformation matrix of grid computing: first of all, respectively to four types of land use suitability figure mask; Then the mask layer on the basis of land type of weight values of transition cost matrix are classified, according to cost 1-0, assign a value of 0 to 4 using the formula (1 -) x x 4 explores the value of cost matrix transformation, again according to the following grading range assignment again, get the corresponding drawing;Finally, the four picture after preprocessing adduct layer for a layer the land type conversion cost.

TABLE III. GRADE RANGE

\begin{tabular}{ccccc}
\hline Range & $0-1$ & $1-2$ & $2-3$ & $3-4$ \\
Evaluation & 1 & 2 & 3 & 4 \\
\hline
\end{tabular}

\section{H. Conversion Cost Score Analysis}

Will the suitability score scores layer, transition layer, coordination cost score layer grid assignment and stack operations, access to space layer optimization results.

\section{EMPIRICAL STUDY}

\section{A. Overview of Study Area}

Ma'anshan City is located in the south bank of lower Yangtze in eastern Anhui Province. West of Shijiu Lake, and adjacent with Lishui County and Gaochun County, east of the Yangtze River, the north of Wuhu suburbs, Wuhu County, Xuancheng County, bordering the south and adjacent to Nanjing. Its location is convenient as riverside offshore and close to the economically developed Yangtze River Delta with relatively flat terrain. In 2010 the city's total area of land was 170,274.05 hectares, including agricultural land 81550.74 hectares, construction land (including land for urban construction, rural residential, land and mining land for infrastructure) 37808.46 hectares of other land (with waterbased, including a small amount of bare ground facilities and agricultural land) 50914.85 hectares, accounting for 47.89 percent of the total land area respectively, $22.20 \%, 29.90 \%$.

\section{B. Index System Construction and Weight Calculation}

Suitability evaluation based on the above principle selected, were established evaluation system for four categories of land in Ma'anshan, then yaahp level software analysis was used in weight determined in accordance with the above procedure. Concrete results in the following table: 
TABLE IV. THE EVALUATION INDEX SYSTEM AND WEIGHT

\begin{tabular}{|c|c|c|c|c|}
\hline Item & factor & $\pi$ reight & factor(10m leve1) & $\pi \in i g h t$ \\
\hline \multirow{12}{*}{$\begin{array}{l}\text { The evaluation } \\
\text { of residential } \\
\text { land }\end{array}$} & Natural factors & 0.0338 & the distance of industrial land & 0.0271 \\
\hline & & & Slope grade & 0.0068 \\
\hline & Demographic factors & 0.2546 & Population density & 0.1910 \\
\hline & & & The bus station distribution & 0.0637 \\
\hline & Commercial Aspects & 0.0810 & Bank distribution & 0.0162 \\
\hline & & & The 1 arge shopp ing ma11 distribution & 0.0648 \\
\hline & & & Distance of the road & 0.0110 \\
\hline & infrastructure & 0.1018 & the distance of the hospital & 0.0298 \\
\hline & & & the distance of the school & 0.0419 \\
\hline & & & the distance of the public & 0.0191 \\
\hline & Land use types & 0.5288 & Local land use types & 0.3525 \\
\hline & & & The effects of land use types & 0.1763 \\
\hline \multirow{8}{*}{$\begin{array}{l}\text { The evaluation } \\
\text { of industrial } \\
\text { land use }\end{array}$} & Natural factors & 0.0538 & the distance of the mining piont & 0.0404 \\
\hline & & & the distance of the river & 0.0135 \\
\hline & Industrial & 0.3406 & First class of industrial & 0.1703 \\
\hline & Agg1omeration & & Second and third class of indus trial & 0.1703 \\
\hline & infrastructure & 0.1082 & the distance of the highray & 0.0865 \\
\hline & & & $\begin{array}{c}\text { the distance of the train station and } \\
\text { port }\end{array}$ & 0.0216 \\
\hline & Land use types & 0.4974 & Regional land use types & 0.3731 \\
\hline & & & $\begin{array}{c}\text { The regional effects of land use } \\
\text { types }\end{array}$ & 0.1244 \\
\hline \multirow{10}{*}{$\begin{array}{l}\text { Evaluation of } \\
\text { comercial land }\end{array}$} & & & the distance of the road & 0.0600 \\
\hline & infrastructure & 0.0856 & the distance of the school & 0.0073 \\
\hline & & & $\begin{array}{l}\text { the distance of the residential } \\
\text { areas }\end{array}$ & 0.0183 \\
\hline & Demographic factors & 0.2537 & Population density & 0.1691 \\
\hline & & & The bus station distribution & 0.0846 \\
\hline & & & The 1 arge shopp ing ma11 distribution & 0.1336 \\
\hline & commercial & 0.2009 & Supernarket distribution & 0.0209 \\
\hline & agglomeration & & Bank distribution & 0.0464 \\
\hline & Land use types & 0.4598 & Local land use types & 0.3066 \\
\hline & & & The effects of land use types & 0.1533 \\
\hline \multirow{6}{*}{$\begin{array}{l}\text { The evaluation } \\
\text { of agricultural } \\
\text { land }\end{array}$} & Natural factors & 0.2605 & terrain & 0.2171 \\
\hline & & & soi1 & 0.0434 \\
\hline & infrastructure & 0.1062 & Village office & 0.0796 \\
\hline & & & river embankment & 0.0265 \\
\hline & Land use types & 0.6333 & Land use types & 0.4222 \\
\hline & & & Effects of land use types & 0.2111 \\
\hline
\end{tabular}

C. Space Superposition Based on Buffer Computing Method

According to the proposed method of establishing a buffer above, the existing layer of Ma'anshan City data grid cells were divided, , based on this evaluation factor to obtain a single layer from the buffer operation. Space superposition operation was carried out according to weights to obtain the results of suitability evaluation of four different types of land use as shown below(the Figure I-IV).

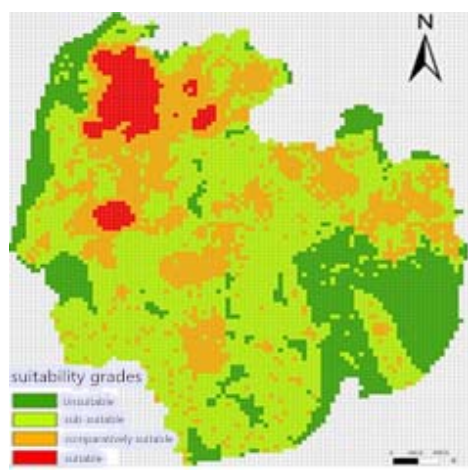

FIGURE I. RESIDENTIAL LAND SUITABILITY EVALUATION RESULT ANALYSIS CHART

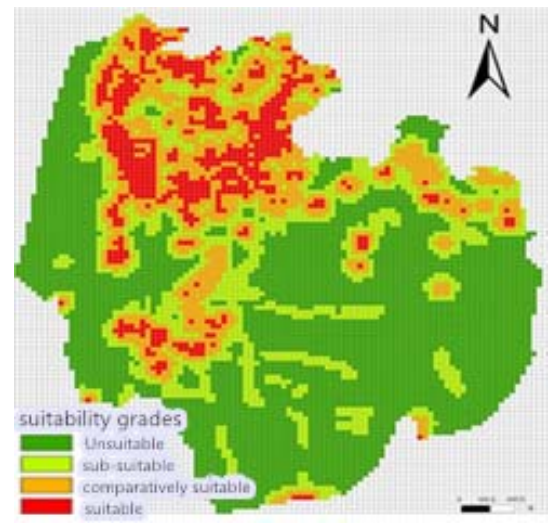

FIGURE II. INDUSTRIAL LAND SUITABILITY EVALUATION RESULT ANALYSIS CHART

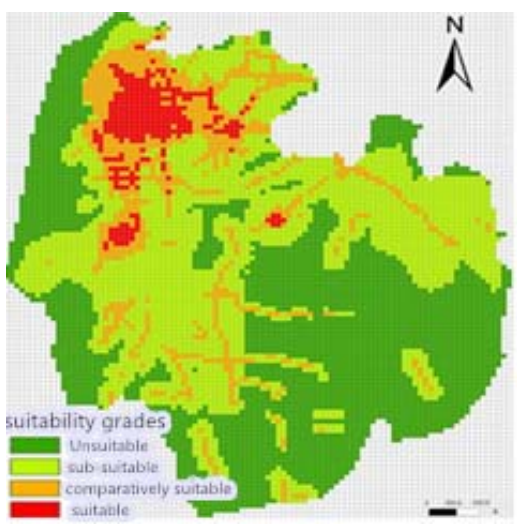

FIGURE III. COMMERCIAL LAND SUITABILITY EVALUATION RESULT ANALYSIS CHART

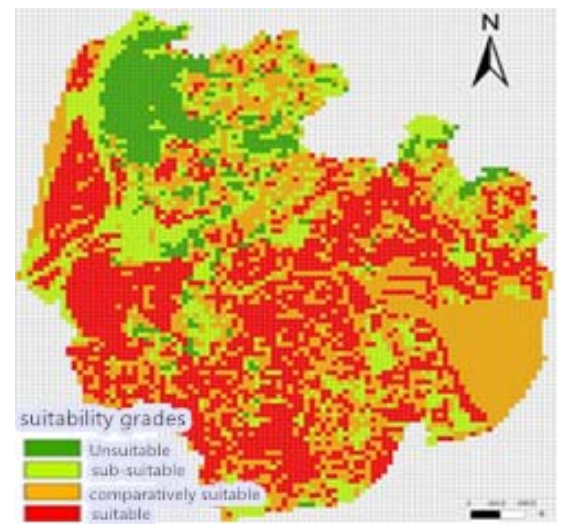

FIGURE IV. THE AGRICULTURAL LAND SUITABILITY EVALUATION RESULT ANALYSIS CHART

According to the weight of four categories land, the above analysis layer overlaying was handled by the grid computing to obtain raster maps of adequate evaluation of the results.

In the analysis layer, the unit value of 2 is suitable land unit, 0 is not suitable unit, namely the need to optimize land units.

The statistics result of various types of land for the grid was 884 grids suitable for industrial use, 143 grids suitable for commercial space, 431 grids suitable for the residential land, 5287 grid suitable for agricultural use. Ma'anshan land use 
raster layers and suitability evaluation raster layers were corrected, after the registration is completed subtracting both available 0 value non-zero value, the layer was reclassified, Value of 0 is assigned to 2 non-zero value assigned 0 , ultimately Ma'anshan City shrewd use of land suitability score is shown below(Figure V).

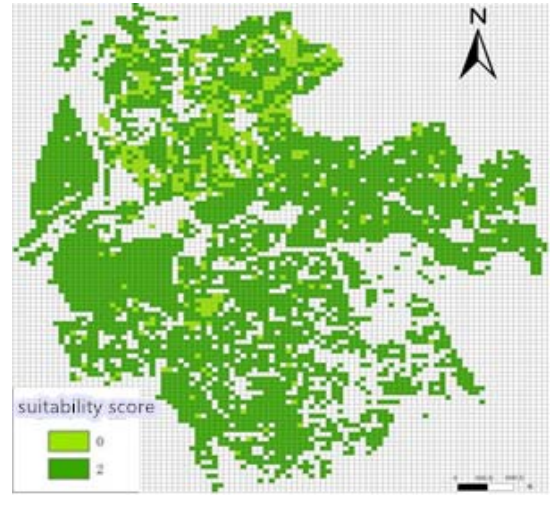

FIGURE V. SUITABILITY SCORE LAYER

\section{Analysis of Spatial Optimization}

On the basis of Ma'anshan City's status of land use types raster layer on the basis of the above described steps of the research process spatial coherence value and cost value conversion layer to establish the following results(FigureVIVII).

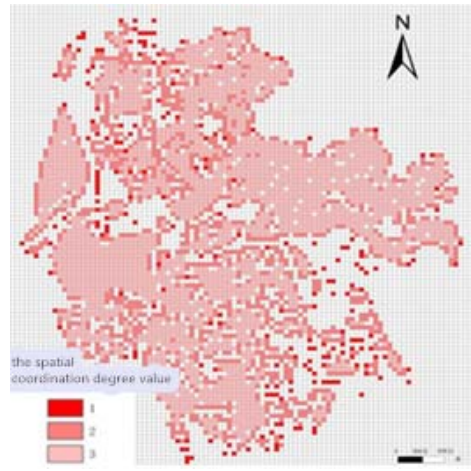

FIGURE VI. THE SPATIAL COORDINATION DEGREE VALUE MAP

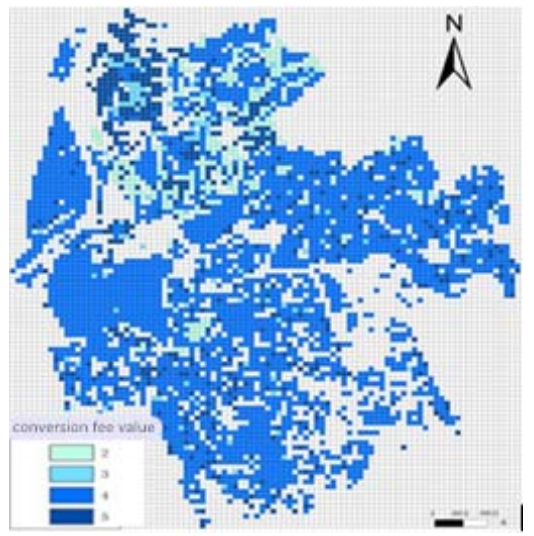

FIGURE VII. CONVERSION FEE VALUE MAP
Overlaying the grid computing resulting above land use suitability value quantization maps, spatial coordination results per graph, the cost of conversions score achievements FIG three layers, the layers obtained integrated value is determined to be optimized grids, eventually forming shrewd use of land space optimization results is as follows.(Figure VIII)

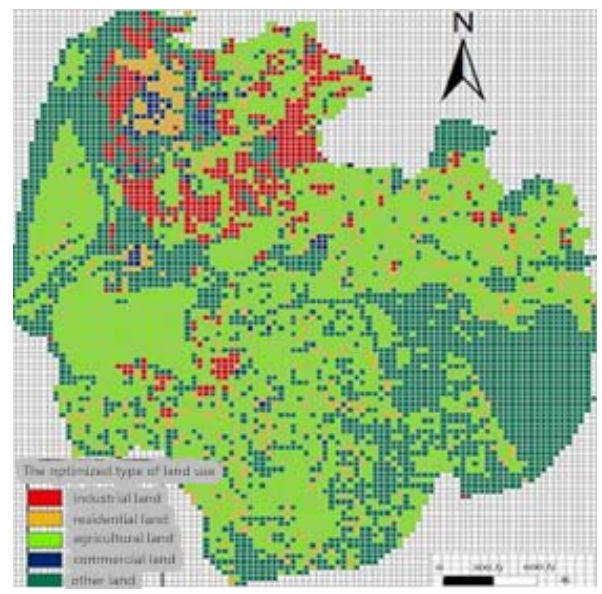

FIGURE VIII. SMART LAND SPACE OPTIMIZATION RESULTS

\section{E. Analysis}

1) In the current land use map can be found Ma'anshan City municipal districts has larger industrial land, industrial land are located in the northwest of the city of Ma'anshan, and mostly along the Yangtze River, this phenomenon is mainly determined by historical reasons. Its distribution showed the distribution-intensive industries gather a certain scale, in favor of industrial progress, thus boosting the economic development of the city, but located in the industrial city of residential land for environmental pollution is not easy to live inside the city, while industrial city gathered occupy a lot of land, including a suitable commercial gold zone for commercial development had a negative impact.

2) Comparison chart with space optimization status map found later by space optimization, Ma'anshan City, various types of land distribution is concentrated on the whole, industrial areas along the Yangtze River has been the formation of industrial land reservation, urban interior scattered agglomeration on the basis of the Town negative direction of the radiation, in order to meet future demand for land for industrial development.

3) Internal part of the program of industrial land converted to residential land and commercial land, while its layout as close to the green parks scenic areas, to ensure environmental benefit, to meet the ecological needs of urban construction.

4) In the land surrounding the mining industry cluster development, formatting industrial parks.

5) Combined with Ma'anshan City development planning, commercial land should be increased in DangTuXian 
possessed scale agglomeration benefits, in line with the general rules of urban development.

\section{RESUlt AND Discussion}

At present, many parts of China's land use form are unreasonable. Human induced land use change, land-use change has reaction to economic development and ecological environment. Land development and heat reduced land use intensity, so that the regional environment has been damaged, restricting sustainable development of regional economy. Based on the concept of urban smart growth, building land use suitability assessment model, providing an image of the type of land space layout optimization mode can provide a reference for a new round of land use planning area. Research process using a suitable method for the evaluation of land use , sophisticated spatial structure optimization provides an important basis for GIS-based spatial overlay buffer space layout optimization for the operation to provide a reliable and intuitive guidance. Case of Maanshan City empirical research, based on smart land use requirements, through layers of different types of land use and related analysis available draped layers Ma'anshan City Land shrewd use unit specific optimization measures need to be optimized: Various types of land within the study area range type distribution should be more concentration, industrial land near the origin of the resources should be used to the combined effect of the development of industrial parks, an appropriate increase in urban commercial and residential land use. In this paper, the process is still shortcomings, such as Analytic Hierarchy Process evaluation factors in determining the weights used in the process to some extent, more subjective, for the judgment lies in the establishment of a matrix summarizing the previous experience and consulting expertise, In addition, the delimitation of the evaluation unit using 500x500 grid size, division of relatively large range, for the evaluation and optimization of the results of certain spatial impact, considering the selection of a more detailed classification method.

\section{ACKNOWLEDGMENT}

This project was supported by College Students Practice and Innovation Training Program of 2014(No. 201410300047) and College Students Practice and Innovation Training Program (No. 201510300098), and the cooperative research with the South of Jiangsu land remediation demonstration center (study on the innovation of land consolidation model in South of Jiangsu modernization construction demonstration zone).

\section{REFERENCES}

[1] BobJentsch.LandUsePlanningandtheConsequencesofSmartGrowth[J].So ciationToday,2006,42:

[2] JerryWeitz.SmartGrowthinaChangingWorld[J].JournaloftheAmericanPla nningAssociation,2008,741:

[3] Cheng Maoji. The evaluation and optimization of [D]. growth in the smart growth of Nanjing Normal University Nanjing city based on 2012;

[4] Tang Xianglong. "Overview of [J]. City Smart Growth, 2009,08:98-102.

[5] Huang Huiming, Casella Sam, Faicp PP. America "smart growth" strategy, and in the case of modern city China thinking of [J]. application, 2007 (5):19-28
[6] Li Shanshan. Smart growth theory of land intensive utilization in Wuhan city based on [D]. strategy research: Master degree thesis of Huazhong University of Science and Technology, 2007

[7] Ren Kui. Land resources under the constraints of regional smart development research [D]. Nanjing: Doctoral Dissertation of Nanjing University, 2009

[8] Ren Kui, week means of livelihood, pollution sources. Based on the smart growth of regional land use structure optimization, in Yixing City, Jiangsu Province as an example [J]. Resources science, 2008,30 (6): 912-918.

[9] Shen Wei. Study on Structure Optimization of [D]. configuration of Ji'nan regional land use based on Smart Growth: Shandong Normal University, 2009

[10] Cao Wei, Zhou means of livelihood, Wu Shaohua,. Smart urban and rural land use index system to measure 1-7 and application [J]. Resource and environment in Yangtze River Basin, 2013,22 (1) the construction.

[11] Cao Wei. The land of urban and rural development under the smart utilization mode research -- Taking Pukou District of Nanjing city as an example [D]. Nanjing: Nanjing University, 2011.

[12] Wang Junling. The stock of land use based on [D]. of Henan Agricultural University City rational growth, 2008.

[13] Qi Zengxiang, Liao Jianjun, Xu Weihua, Ni Yongming. Qinling Mountains mountain settlement GIS land suitability evaluation based on 2015,04:. [J]. Journal of ecology.

[14] Lin Yan Xu, to the Ling, Zhang Hong. Based on GIS in the mountainous cities and towns space to expand the land suitability evaluation in Dayao County for cases. Journal of Anhui Agricultural Sciences, 2015,16:303306+319.

[15] Yao Dandan, Yang Wenhui, Miao Fang, Chen Jun, Lu Hanyu. GIS based in Sichuan Province agricultural land suitability evaluation of [J]. computing techniques for geophysical and geochemical exploration, 2015,03:403-408.

[16] Liao Hongqiang, Qiu Yong, Yang Xia, Wang Xinggang, Ge Renwei. Determination of the weights of the [J]. Mechanical Engineer for the application of AHP, 2012,06:22-25.

[17] [jian-e Chang, Jiang Taili. Level analysis method to determine weight [J] Wuhan University of Technology (Information \& Management Engineering Edition), 2007,01:153-156.

[18] Yu Jin by, Wang Hong, Gan Lin, Shi Tao Zhang. AHP in determining the weights of evaluation indexes system [J]. China Medical equipment, 2013,12:44-47. 